DOI: 10.5604/01.3001.0013.0877

\title{
EMG FIELD ANALYSIS IN DYNAMIC MICROSCOPIC/NANOSCOPIC MODELS OF MATTER
}

\author{
Pavel Fiala ${ }^{1}$, Karel Bartušek ${ }^{2}$, Jarmila Dědková ${ }^{3}$, Premysl Dohnal ${ }^{3}$ \\ ${ }^{1}$ SIX Research Center, Department of Theoretical and Experimental Electrical Engineering, ${ }^{2}$ Institute of Scientific Instruments of the ASCR v.v.i., \\ ${ }^{3}$ Brno University of Technology, Faculty of Electrical Engineering and Communication, Department of Theoretical and Experimental Electrical Engineering
}

\begin{abstract}
We discuss a numerical model (macro/micro/nanoscopic) to enable more accurate analysis of electro-hydro-dynamic (EMHD) processes in water at the level of atoms. Dedicated experiments have shown that inserting a relatively homogeneous periodic structure (deionized, degassed, or distilled $\mathrm{H}_{2} \mathrm{O}$ ) in a magnetic field will influence the atomic basis, molecules, and relevant bonds. In this context, the present paper focuses on the designing, analysis, and evaluation of the behavior of an extensive system that represents $\mathrm{H}_{2} \mathrm{O}$ from the microscopic perspective, and it also outlines the properties and changes of the bonds in the examined water samples. Complementarily, a simple example is used to define the results obtained from analyses of the generated spiral static gradient magnetic and non-stationary gradient electromagnetic fields from the frequency range of $f=1$ GHz to $10 \mathrm{GHz}$.
\end{abstract}

Keywords: multiscaling, modeling, water, cluster, atoms, molecules, structure, matter, low-level measurement

\section{ANALIZA POLA EMG W MIKRO/NANOSKOPOWYCH MODALECH MATERII}

Streszczenie. W artykule przedyskutowano (makro/mikro/nanoskopowy) model numeryczny przeznaczony do dokładniejszej analizy procesów elektrohydrodynamicznych (EMHD) w wodzie na poziomie atomowym. Przeprowadzone $w$ tym celu eksperymenty wykazały, że wprowadzenie względnie jednorodnej struktury okresowej (dejonizowanej, odgazowanej lub destylowanej wody w polu magnetycznym wptynie na strukture atomowa, molekuty $i$ odpowiednie wiazania. W tym kontekście niniejszy artykut koncentruje się na projektowaniu, analizie i ocenie zachowania rozległego systemu, który reprezentuje $\mathrm{H}_{2} \mathrm{O}$ z perspektywy mikroskopowej, a także nakreśla właściwości i zmiany wiązań w badanych próbkach wody. Dodatkowo, zastosowano prosty przykład stuży do definiowania uzyskanych wyników na podstawie analizy statycznych, spiralnych statycznych gradientowych i niestacjonarnych gradientowych pól elektromagnetycznych w zakresie częstotliwości od $1 \mathrm{GHz}$ do $10 \mathrm{GHz}$.

Słowa kluczowe: multiscaling, modelowanie, woda, klaster, atomy, cząsteczki, budowa, materia, pomiar niskiego poziomu

\section{Introduction}

Since ancient times, four basic elements have been contemplated as the structural components of the world: fire, earth, air, and water, with the last of the substances considered the central factor to determine the properties of matter. such an approach was proposed by, for example, Thales of Miletus (c. 624 - c. 546 BC) and Plato (c. 424 - c. 348 BC).

More recently, multiple authors discussed the behavior of water structures, including those in ice; this group of scientist comprised, among others, Henry Frank and Wen-Yang Wen, who outlined the concept of "flickering clusters of molecules" (1957), $[17,29]$, elaborating on water clustering hypotheses and hydrogen bonding in a water molecule.

In the physical sense, the real-world behavior of water characterized by the formula ${ }^{1} \mathrm{H}_{2}{ }^{16} \mathrm{O}$ is merely hypothetical and demonstrative: Even a single molecule of water, or 'just $\mathrm{H}_{2} \mathrm{O}$ ', may behave in the ortho or para manners when employed within a real task (experiment). Relevant analyses performed previously discussed water from the quantitative perspective only, regardless of its electromagnetic condition [18]. The known isotopes of hydrogen and oxygen include ${ }^{1} \mathrm{H},{ }^{2} \mathrm{H},{ }^{3} \mathrm{H},{ }^{4} \mathrm{H},{ }^{5} \mathrm{H},{ }^{6} \mathrm{H},{ }^{7} \mathrm{H},{ }^{12} \mathrm{O}$, ${ }^{13} \mathrm{O},{ }^{14} \mathrm{O},{ }^{15} \mathrm{O},{ }^{16} \mathrm{O},{ }^{17} \mathrm{O},{ }^{18} \mathrm{O},{ }^{19} \mathrm{O},{ }^{20} \mathrm{O},{ }^{21} \mathrm{O},{ }^{22} \mathrm{O},{ }^{23} \mathrm{O}$, and ${ }^{24} \mathrm{O}$, but only ${ }^{1} \mathrm{H},{ }^{2} \mathrm{H},{ }^{16} \mathrm{O},{ }^{17} \mathrm{O}$, and ${ }^{18} \mathrm{O}$ are stable; the remaining forms are unstable, subjected to disintegration.

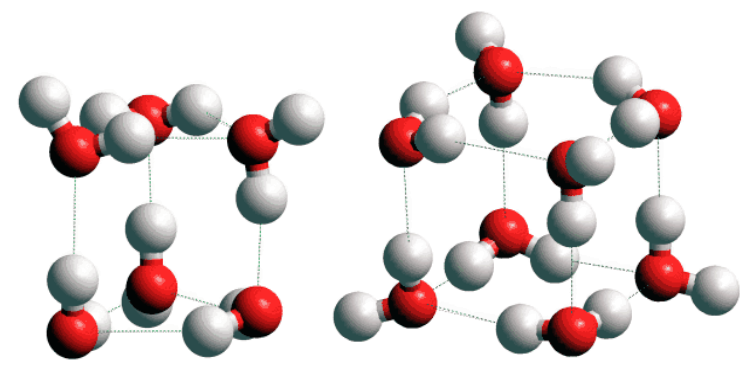

Fig. 1. Small clusters of $\mathrm{H}_{2} \mathrm{O}$ molecules with hydrogen bonds: a) $\left(\mathrm{H}_{2} \mathrm{O}\right)_{6}$ 'prism' [8, 35]; b) $\left(\mathrm{H}_{2} \mathrm{O}\right)_{8}$ 'cube' [9]

Considering the percentages defining the presence of substances on Earth, water is a major structural element, and it also constitutes a binding component in inorganic substances. The reason for the latter condition consists in the electric and magnetic fields of a water molecule and the related bonds to other atoms of the periodic table. Multiple water molecules close to one another are then bonded by electromagnetic forces to shape periodic formations (displayable via crystalographic methods at a later time), creating a comprehensive, dynamic cluster $[2,7$, $12,13,20,21,23,31,34,39]$. Significant instruments to facilitate the understanding of water molecular bonds rest in numerical models of the electromagnetic field and experimental measuring methods that can repeatedly evaluate electromagnetic field quantities and analyze - retroactively, according to numerical models - states at the atomic level (Rahman and Stillinger [20, 21, 31, 34, 39]).

Chaplin [7] suggested an interesting structure of water molecules, which, thanks to hydrogen bonds, clarifies certain anomalous properties of water.

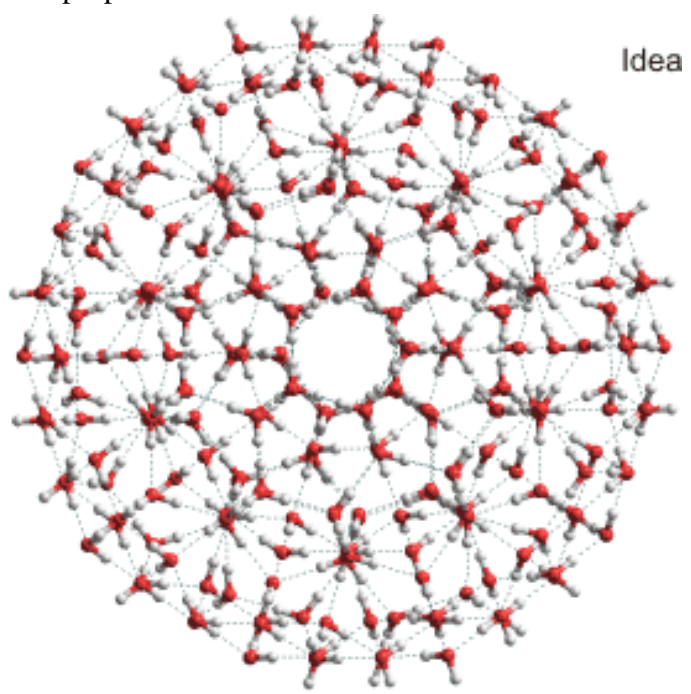

Fig. 2. Presumed clusters of $\mathrm{H}_{2} \mathrm{O}$ molecules [36] with hydrogen bonds [6, 32, 33], $\left(\mathrm{H}_{2} \mathrm{O}\right)_{280}$

In the given context, our paper outlines the design of a geometrical model to form a special, spiral, "gradient" magnetic field, using relevant analyses for the subsequent verification of changes in structures determined by hydrogen bridges in the inserted water samples. The components of the electromagnetic 
field and the vector of magnetic flux density B and electric field intensity $\mathrm{E}$ exhibit a high degree of inhomogeneity, thus forming a gradient in the monitored portion of space. The analysis of the results obtained from the model indicates the electric and magnetic field distribution and is instrumental for setting the conditions of further experiments.

\section{Numerical model of the scaled problem}

Based on previous modeling of the effects exerted by magnetic fields on the elementary particles of matter $[11,15]$, the adopted simulation procedure can be considered appropriate and suitable for capturing the influence of an external magnetic field on the electro-magneto-hydro-dynamic (EMHD) processes in elementary particles of matter [16], namely, in the dynamic bonds of matter as a periodic system. The fundamental force acting on the elements via an external electromagnetic (EMG) field having a non-zero electric charge $q$ is written as

$$
\boldsymbol{F}=q(\boldsymbol{E}+\boldsymbol{v} \times \boldsymbol{B}),
$$

where $\boldsymbol{B}$ is the vector magnetic flux density in the space of a moving electrically charged particle, $q$ denotes the volume density, $v$ represents the mean velocity of the charged particle, and $\boldsymbol{E}$ is the electric intensity vector. Then, the specific force $\boldsymbol{f}$ acting on the moving electrically charged "particles" with a charge $q$ is

$$
\boldsymbol{f}=\frac{\mathrm{d}\left(N_{q} q\right)}{\mathrm{d} V}(\boldsymbol{E}+\boldsymbol{v} \times \boldsymbol{B}),
$$

where $N_{\mathrm{q}}$ denotes the number of electrically charged particle regions, and $V$ is the volume around the electric charges $N_{\mathrm{q}}$. This force will change the charged particle trajectory and the quantity of energy $W_{\mathrm{q}}$, thus effecting a change of the particle oscillation frequency $\omega$. This can be expressed in the form

$$
\Delta \omega_{\mathrm{p}}=\frac{\partial \omega}{\partial W} \Delta W_{q},
$$

where $\omega_{\mathrm{p}}$ is the oscillation frequency of an electrically charged particle, $\Delta \omega_{\mathrm{p}}$ denotes the change of the particle oscillation frequency, and $\Delta W$ is the change of the energy of the electrically charged particle. The dependence of the electrically charged region-particle frequency on the values of the EMG field can be expressed as

$$
\omega_{\mathrm{p}} \approx \sqrt{\frac{|q(\boldsymbol{E}+\boldsymbol{v} \times \boldsymbol{B})|}{m_{\mathrm{p}} x}},
$$

where $x$ is the distance of an oscillating particle with an electric charge $q$, which moves and changes trajectory at a velocity $\boldsymbol{v}$, and $m_{\mathrm{p}}$ denotes the mass of an electrically charged particle regions in the EMG field. The numerical model will be derivable from the formulation of the reduced Maxwell's equations as

$$
\operatorname{rot} \boldsymbol{E}=-\frac{\partial \boldsymbol{B}}{\partial t}, \operatorname{rot} \boldsymbol{H}=\boldsymbol{J}_{S}+\frac{\partial \boldsymbol{D}}{\partial t}, \operatorname{div} \boldsymbol{B}=\boldsymbol{O}, \operatorname{div} \boldsymbol{D}=\rho,
$$

where $\boldsymbol{H}$ is the magnetic field intensity vector, $\boldsymbol{J}_{\mathrm{S}}$ is the field source current density vector, and $\boldsymbol{D}$ denotes the electric flux density vector. Respecting the continuity equation

$$
\operatorname{div} \boldsymbol{J}_{T}=-\frac{\partial \rho}{\partial t}
$$

where $\boldsymbol{J}_{\mathrm{T}}$ is the total current density vector, the EMG field functions are expressed via the scalar electric potential $\phi_{\mathrm{e}}$ and the vector magnetic potential $\boldsymbol{A}$ [10].

By applying the Galerkin method to find the functional minimum (as described in, for example, reference [37]) and considering the boundary conditions, we obtain the numerical model as a system of non-linear equations to be solved by standard methods in the ANSYS FEM system [40].
The coupling of both models is formulated using equation (1) and the following formula:

$$
N_{q} q(\boldsymbol{E}+\boldsymbol{v} \times \boldsymbol{B})-\frac{N_{q} q}{\gamma}\left(\frac{\partial(\varepsilon \boldsymbol{E})}{\partial t}\right)=\frac{m \mathrm{~d} \boldsymbol{v}}{\mathrm{d} t}+l \boldsymbol{v}+k \int_{T} \boldsymbol{v} \mathrm{d} t .
$$

The total current density $\boldsymbol{J}_{\mathrm{T}}$ with respect to the velocity of moving electrically charged region-particles and considering the microscopic structure model of matter then is

$$
\begin{aligned}
& \boldsymbol{J}_{\mathrm{T}}=\frac{\gamma}{N_{q} q}\left(\frac{m \mathrm{~d} \boldsymbol{v}}{\mathrm{d} t}+l \boldsymbol{v}+k \int_{t} \boldsymbol{v} \mathrm{d} t\right)-\frac{\partial(\varepsilon \boldsymbol{E})}{\partial t}+\gamma(\boldsymbol{E}+\boldsymbol{v} \times \boldsymbol{B}), \\
& \operatorname{rot} \boldsymbol{H}=\frac{\gamma}{N_{q} q}\left(\frac{m \mathrm{~d} \boldsymbol{v}}{\mathrm{d} t}+l \boldsymbol{v}+k \int_{t} \boldsymbol{v} \mathrm{d} t\right)- \\
& -\frac{\partial(\varepsilon \boldsymbol{E})}{\partial t}+\gamma(\boldsymbol{E}+\boldsymbol{v} \times \mathbf{B})+\operatorname{rot}(\boldsymbol{v} \times \boldsymbol{D}) \\
& \operatorname{rot} \boldsymbol{E}=-\frac{\partial(\boldsymbol{B})}{\partial t}+\gamma(\boldsymbol{E}+\boldsymbol{v} \times \boldsymbol{B})+\operatorname{rot}(\boldsymbol{v} \times \boldsymbol{B}),
\end{aligned}
$$

where $m$ is the $N_{\mathrm{q}}$ particle mass $m_{0}$ given by the formula, $\gamma$ is the conductivity of the environment from the macroscopic view, $l$ denotes the damping coefficient, and $k$ represents the stiffness coefficient of the ambient environment.

As regards the relationship between the moving structure of an $\mathrm{H}_{2} \mathrm{O}$ molecule as a micro/nanoscopic model of matter and the static ambient environment (conductor), namely, a dielectric having a pre-selected configuration, their mutual motion must be respected $[14,38]$. Thus, we obtain a hybrid numerical model that will significantly simplify the analysis, respecting the properties of the task at the boundary of the models. The current density $\boldsymbol{J}_{\mathrm{T}}$ from formula (7) then changes to a form considering relative motion with an instantaneous velocity $v(\mathrm{t})$. We have

$$
\begin{aligned}
& \boldsymbol{J}_{\mathrm{T} \square}^{\prime}=\frac{\gamma}{N_{q} q}\left(\frac{m \mathrm{~d}\left(v_{\Delta}+\mathrm{j} c \boldsymbol{u}_{t}\right)}{\mathrm{d} t}+l\left(\boldsymbol{v}_{\Delta}+\mathrm{j} c \boldsymbol{u}_{t}\right)+k \int_{t}\left(\boldsymbol{v}_{\Delta}+\mathrm{j} c \boldsymbol{u}_{t}\right) \mathrm{d} t\right) \\
& \left(1-\frac{v^{2}}{c^{2}}\right)^{-\frac{1}{2}}+\mathrm{j} c \frac{N_{q} q}{\partial V}\left(1-\frac{v^{2}}{c^{2}}\right)^{-\frac{1}{2}} \boldsymbol{u}_{t}-\frac{\partial(\varepsilon \boldsymbol{E})}{\partial t}\left(1-\frac{v^{2}}{c^{2}}\right)^{-\frac{1}{2}} \\
& +\gamma\left(\boldsymbol{E}+\left(v_{\Delta}+\mathrm{j} c \boldsymbol{u}_{t}\right) \times \boldsymbol{B}\right)\left(1-\frac{v^{2}}{c^{2}}\right)^{-\frac{1}{2}}+\operatorname{rot}\left(\left(v_{\Delta}+\mathrm{j} c \boldsymbol{u}_{t}\right) \times \boldsymbol{D}\right)\left(1-\frac{v^{2}}{c^{2}}\right)^{-\frac{1}{2}}
\end{aligned}
$$

The relationship between the macroscopic model of the geometrical part of the EMG field and the quantum-mechanical (microscopic) model of bound particles is expressed via application of current density (7) and by the above formulas (5), as follows:

$$
\begin{aligned}
& \operatorname{rot} \boldsymbol{H}_{\square}^{\prime}=\frac{\gamma}{N_{q} q}\left(\frac{m \mathrm{~d}\left(\boldsymbol{v}_{\Delta}+\mathrm{j} c \boldsymbol{u}_{t}\right)}{\mathrm{d} t}+l\left(\boldsymbol{v}_{\Delta}+\mathrm{j} c \boldsymbol{u}_{t}\right)+k \int_{t}\left(\boldsymbol{v}_{\Delta}+\mathrm{j} c \boldsymbol{u}_{t}\right) \mathrm{d} t\right) \\
& \left(1-\frac{v^{2}}{c^{2}}\right)^{-\frac{1}{2}}+\mathrm{j} c \frac{N_{q} q}{\partial V}\left(1-\frac{v^{2}}{c^{2}}\right)^{-\frac{1}{2}} \boldsymbol{u}_{t}-\frac{\partial(\varepsilon \boldsymbol{E})}{\partial t}\left(1-\frac{v^{2}}{c^{2}}\right)^{-\frac{1}{2}} \\
& +\gamma\left(\boldsymbol{E}+\left(\boldsymbol{v}_{\Delta}+\mathrm{j} c \boldsymbol{u}_{t}\right) \times \mathbf{B}\right)\left(1-\frac{v^{2}}{c^{2}}\right)^{-\frac{1}{2}} \\
& +\operatorname{rot}\left(\left(\boldsymbol{v}_{\Delta}+\mathrm{j} c \boldsymbol{u}_{t}\right) \times \boldsymbol{D}\right)\left(1-\frac{v^{2}}{c^{2}}\right)^{-\frac{1}{2}}
\end{aligned}
$$


When respecting the structure dynamics of the tested samples of $\mathrm{H}_{2} \mathrm{O}$ (7-8) (Fig. 3) in a hybrid model including both a macroscopic electromagnetic field (5)-(6) [37] and the micro/nanoscopic interpretation of matter (1)-(4), (7)-(8), and considering the effects of relative motion at the boundaries of the macro-, micro-, and nanoscopic model (9), (10), the focus is on the external response of the system. The external response (and its accuracy) of an EMG field is important from the perspective of physically verifiable experiments and measurement of the water sample dynamics. In Stratton's theory of the electromagnetic field [37], it is possible to link and evaluate time density $\tau$, which embodies a binding element in explaining nontrivial effects at the interface of macroscopic and nanoscopic models [3, 4, 5, 27, 38]; relevant experiments can then be conceived accordingly.

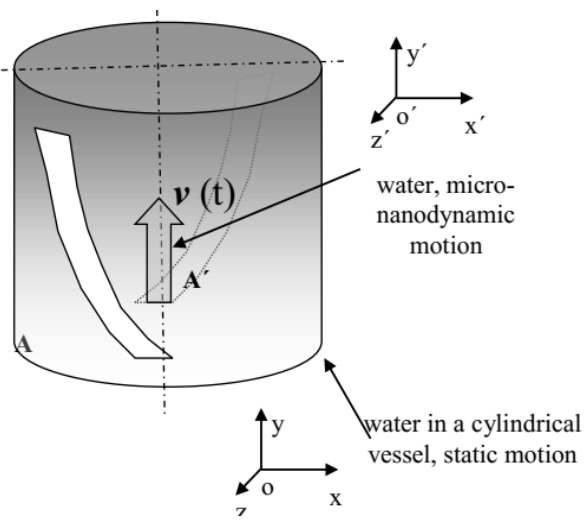

Fig. 3. The relationship between two moving systems (a macro/microscopic model of matter) that involve objects $A$ and $A^{\prime}$, moving mutually at a velocity $v(t)$

The known quantities from the perspective of a macroscopic model of matter (an external field) are magnetic flux, current flux $I$, and electric flux having a magnitude $q$ :

$$
\phi=\iint_{\Gamma} \boldsymbol{B} \cdot d \boldsymbol{S} I=\iint_{\Gamma} \boldsymbol{J} \cdot d \boldsymbol{S} \quad q=\iint_{\Gamma} \boldsymbol{D} \cdot d \boldsymbol{S},
$$

where $S$ is the vector of the oriented boundary (in a 3D model of the plane), and $\Gamma$ represents the boundary of the area in which the flux is evaluated. If the model with a scale difference expressed in orders comprises a moving element of the system, it becomes easier to describe the state and effect of the superposed electromagnetic field by expressing the time flux density. The time flux can be different or inhomogeneous in parts of the area; it is then possible to write

$$
t=\iint_{\Gamma} \tau \cdot d \mathbf{S}
$$

After expanding the expression with the time flux density for the Cartesian coordinate system o, x, y, z, Fig. 4, we have

$$
\boldsymbol{\tau}=\frac{d t}{d y d z} \boldsymbol{u}_{x}+\frac{d t}{d z d x} \boldsymbol{u}_{y}+\frac{d t}{d x d y} \boldsymbol{u}_{z} ;
$$

the instantaneous velocity of an elementary electrically charged object is subsequently given in the directions $\mathrm{x} v_{\mathrm{x}}(\mathrm{t}), \mathrm{y} v_{\mathrm{y}}(\mathrm{t})$, and $z$ $v_{\mathrm{z}}(\mathrm{t})$ :

$$
\boldsymbol{\tau}=\frac{1}{v_{y}(t) d z} \boldsymbol{u}_{x}+\frac{1}{v_{z}(t) d x} \boldsymbol{u}_{y}+\frac{1}{v_{x}(t) d y} \boldsymbol{u}_{z} .
$$

To compare the energies, we can consider the functions $f$ and $g$ equal (14). have

In the context of the relevant claim immediately above, we

$$
f(\boldsymbol{E} \times d \ell)=g\left(\boldsymbol{\tau}^{-1} \times \boldsymbol{B}\right) .
$$

Then, for the component $\mathrm{x}$ of the time density $\tau_{\mathrm{x}}$, we can write

$$
\begin{gathered}
E_{x} d y \boldsymbol{u}_{z}+E_{x} d z \boldsymbol{u}_{y}=\frac{1}{\tau_{x}} B_{y} \boldsymbol{u}_{z}-\frac{1}{\tau_{x}} B_{z} \boldsymbol{u}_{y}, \\
E_{x} d y \boldsymbol{u}_{z}+E_{x} d z \boldsymbol{u}_{y}=v_{y} d z B_{y} \boldsymbol{u}_{z}-v_{y} d z B_{z} \boldsymbol{u}_{y} .
\end{gathered}
$$

The above formulas illustrate the relationships between elementary charges of matter in a dynamic system; such bonds are both mutual, namely, between the individual charges, and relating to an external system from the perspective of reciprocal relative motion (7)-(10), assuming the properties of the components of the electric and the magnetic fields. The evaluation of the power density transmission in the modeled system is written as

$$
\boldsymbol{\Pi}=\boldsymbol{E} \times \boldsymbol{H}
$$

or, comprising also the electromagnetic field components, as

$$
\boldsymbol{\Pi}=E_{x} H_{y} \boldsymbol{u}_{z}-E_{x} H_{z} \boldsymbol{u}_{y}
$$

To express the dynamic system (with instantaneous velocities $\boldsymbol{v}$ ), we can use

$$
\Pi=(v \times B) \times(v \times D) .
$$

We have

$$
\Pi=
$$$$
=\boldsymbol{u}_{x}\left(\left(v_{z} B_{x}-v_{x} B_{z}\right)\left(v_{x} D_{y}-v_{y} D_{x}\right)-\left(v_{x} B_{y}-v_{y} B_{x}\right)\left(v_{z} D_{x}-v_{x} D_{z}\right)\right)
$$$$
+\boldsymbol{u}_{y}\left(\left(v_{x} B_{y}-v_{y} B_{x}\right)\left(v_{y} D_{z}-v_{z} D_{y}\right)-\left(v_{y} B_{z}-v_{z} B_{y}\right)\left(v_{x} D_{y}-v_{y} D_{x}\right)\right)
$$$$
+\boldsymbol{u}_{z}\left(\left(v_{y} B_{z}-v_{z} B_{y}\right)\left(v_{z} D_{x}-v_{x} D_{z}\right)-\left(v_{z} B_{x}-v_{x} B_{z}\right)\left(v_{y} D_{z}-v_{z} D_{y}\right)\right)
$$

For the $\tau_{\mathrm{x}}$, the Poynting vector is

$$
\begin{aligned}
& \boldsymbol{\Pi}=\boldsymbol{u}_{y}\left(\left(v_{y} B_{z}-v_{z} B_{y}\right)\left(v_{y} D_{x}\right)\right)+\boldsymbol{u}_{z}\left(\left(v_{y} B_{z}-v_{z} B_{y}\right)\left(v_{z} D_{x}\right)\right) \\
& E_{x} H_{y} \boldsymbol{u}_{z}-E_{x} H_{z} \boldsymbol{u}_{y}= \\
& =\boldsymbol{u}_{y}\left(\left(v_{y} B_{z}-v_{z} B_{y}\right)\left(v_{y} D_{x}\right)\right)+\boldsymbol{u}_{z}\left(\left(v_{y} B_{z}-v_{z} B_{y}\right)\left(v_{z} D_{x}\right)\right)
\end{aligned}
$$

The above formulas (15), (16), (18), (20) and Figs. 4, 5 allow us to form an idea of how an inhomogeneous field acts on the dynamics of elementary matter from the nanoscopic perspective, represented via instruments such as the physical and chemical models utilized for the investigated sample of $\mathrm{H}_{2} \mathrm{O}$. We thus can, for example, predict the influence exerted by the macroscopic setting of an external (static or non-stationary) electromagnetic field on an elementary particle of matter, namely, water. Considering the modeled arrangement of a large set of water molecules, it is then possible to evaluate the electromagnetic and physical properties of the entire sample and to modify the experimental measurement parameters; after these stages, the results verification procedure can be adjusted as needed.

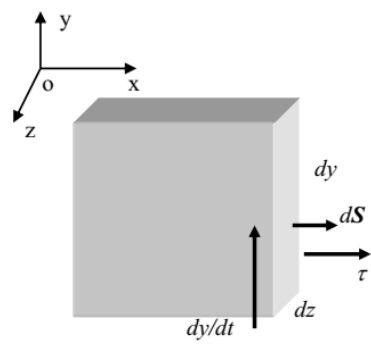

a)

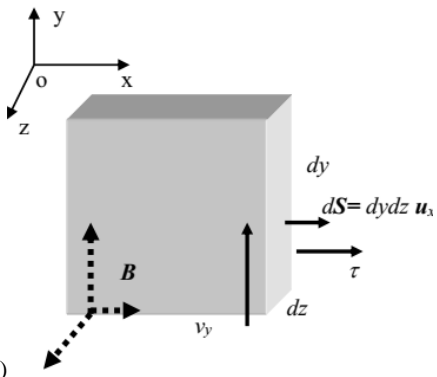

Fig. 4. The schematic quantities to express: a) the time flux density $\tau$, and $b$ ) the external EMG field
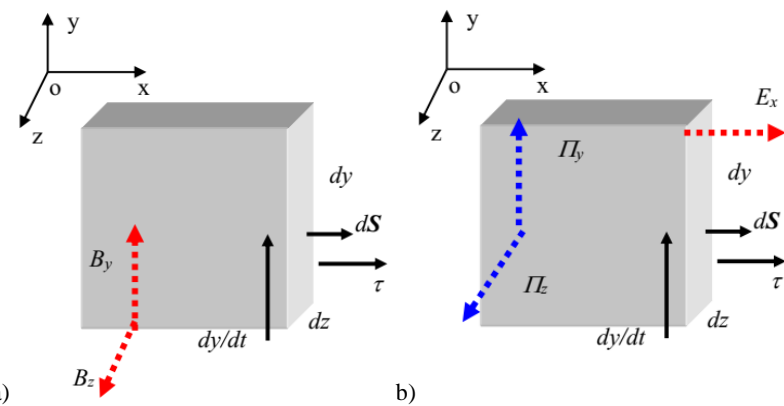

Fig. 5. The schematic quantities from relations (5-6) to express: a) the function $g$, and $b$ ) the function $f$ (the Poynting vector $\Pi$, (16-17)) 
The conditions for setting the external magnetic field were adopted from previous versions of our experiments and their verifications. In this context, a significant factor rests in the degree of inhomogeneity of the external field on the macroscopic scale. We then have $\partial \mathrm{Bx} / \partial \mathrm{x} \neq 0, \partial \mathrm{By} / \partial \mathrm{y} \neq 0$, and $\partial \mathrm{Bz} / \partial \mathrm{z} \neq 0$, respecting the curl character of the field [31].

\section{Analyzing the electromagnetic field model}

In order to create conditions typical of the external magnetic field $\boldsymbol{B}$ in the numerical model characterized by formulas (7), (9), (18), we set up a geometrical model according to Fig. 5a or 5b. The task employs either two plastically modifiable permanent magnets (PM), $\boldsymbol{M}_{1}$ and $\boldsymbol{M}_{2}$, whose magnetization is oriented as shown in Fig. 6a, or an electric wire (Fig. 6b). The magnetic field, preset in the indicated manner, then forms a spiral gradient magnetic field inside the configuration space; this latter field then acts on the microscopic model of matter, or the tested water sample, by influencing the dynamics of the moving components of matter (18)-(20) having a velocity $v(\mathrm{t})$ and an electric charge $q$. A similar magnetic field exhibiting a spiral magnetic structure is discussed in paper [1] and also visualized here in Fig. 6b below, where the source is a conductor excited by a harmonic signal with a frequency of, for example, $f=1-10 \mathrm{GHz}$.

We analyzed the magnetic field associated with the spiral arrangement of the permanent magnets and, using Ansys APDL [40], created a mathematical model convenient for the EMHD setting (9-10), $\phi R_{1}=150 \mathrm{~mm}, l=200 \mathrm{~mm}$. The distribution of the static magnetic field, namely, the module of magnetic flux density $B$ for the surface of the cylinder illustrated in Fig. 6a, is presented in Fig. 7; the module of electric field intensity $E(\mathrm{t})$, $f=1 \mathrm{GHz}$, for the surface of the sphere illustrated in Fig. $6 \mathrm{~b}$ is displayed in Figs. 8-14.

Following the analysis of the external EMG field model, the electric and magnetic field distribution was interpreted at multiple scales. The first, or global, one is shown in Fig. 7a; the maxima of the module of magnetic flux density $B$ are within units of T. At the second scale, the field distribution has to be selected such that the vicinity of the permanent magnets is captured; the corresponding units are those of $[\mathrm{mT}]$, Fig. $7 \mathrm{~b}$. The third level to represent the magnetic field is within units of $\mu \mathrm{T}$. The properties and shape of the magnetic field in the majority volume of the cylinder can be outlined by drawing the vectors of magnetic flux density $\boldsymbol{B}$, as indicated in, for example, Figs. 7a, b.
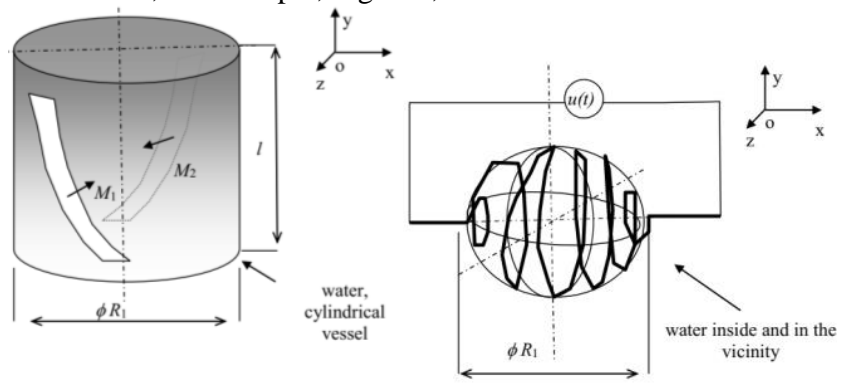

a)

b)

Fig. 6. A geometrical model of the spiral arrangement of the PMs in a cylinder (a), the spherical alternative $(b)$

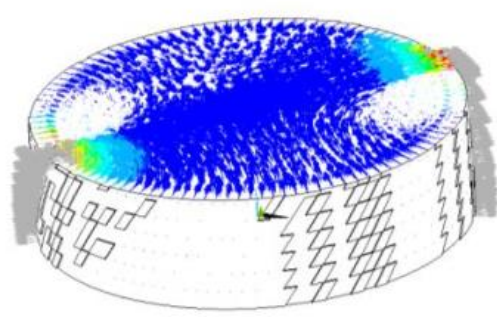

a)

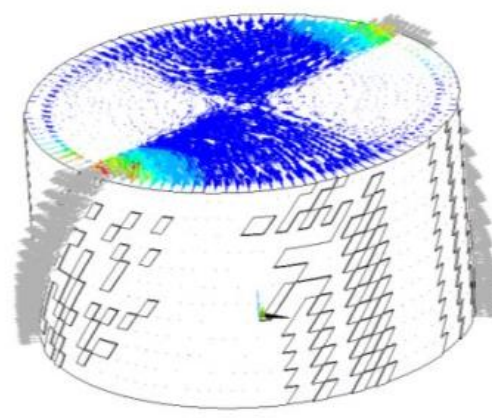

b)

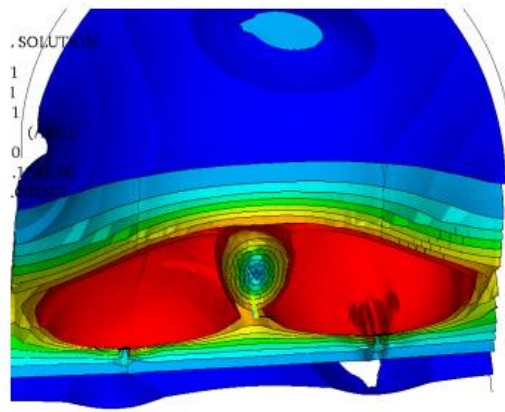

c)

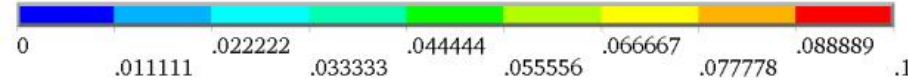

Fig. 7. The evaluation of the magnetic flux density vector B $[T]$ in the modeled spiral arrangement of the permanent magnets, related to the volume of the cylinder: a) at one third of the cylinder height; $b$ ) at one half of the cylinder height; $c$ ) the magnetic flux density module B[T]

\section{Results of the conductivity measurement}

To determine the liquid water conductivity value [5], we used an automatized measurement of $C$ and $\operatorname{tg} \delta$ with two structurally different three-electrode systems and an Agilent 4284A analyzer. This process comprised two cycles performed at the Faculty of Electrical Engineering and Communication, Brno University of Technology.

Before each of the runs, we had to identify a suitable technique to clean the electrode systems such that the cycles showed the least possible degree of contamination by the previous tasks. Both of the three-electrode systems were cleaned via triple rinsing with demineralized water.
Series No. 1 subsumed twenty tasks: ten focused on the reference samples and another ten including the treated ones. The electrode system in use was filled with the selected type of water and rinsed three times; subsequently, the data in the frequency band of $20 \mathrm{~Hz}$ to $2 \mathrm{MHz}$ were measured automatically and stored in an MS Excel worksheet. The measurement conditions are specified in Table 1 [5]; the results and comparison of the untreated and treated water samples can be obtained from Table 2 [5].

The conductivities of the reference and the treated water samples related to frequencies are presented in Fig. 15.

Table 1. Measurement Series No. 1: Details

\begin{tabular}{|c|c|c|c|c|c|c|c|}
\hline Date & Time $[\mathrm{h}]$ & Ambient temperature $\left[{ }^{\circ} \mathrm{C}\right]$ & Pressure $[\mathrm{hPa}]$ & Moisture rate $[\%]$ & Altitude $[\mathrm{m}]$ & AC voltage $[\mathrm{V}]$ & Frequency range $[\mathrm{Hz}]$ \\
\hline $12 / 18 / 2012$ & $9-12$ & 24.7 & 1022.9 & 25 & 320 & 0.5 & $20-2 \cdot 10^{6}$ \\
\hline
\end{tabular}

Table 2. Measurement Series No. 1: Conductivities of the Water Samples

\begin{tabular}{|c|c|c|}
\hline Sample & $\gamma[\mu \mathrm{S} / \mathrm{cm}]$ & $\gamma_{s d}[\mu \mathrm{S} / \mathrm{cm}]$ \\
\hline Reference & 11.60885 & 0.462011 \\
\hline Treated & 6.619136 & 0.129992 \\
\hline
\end{tabular}




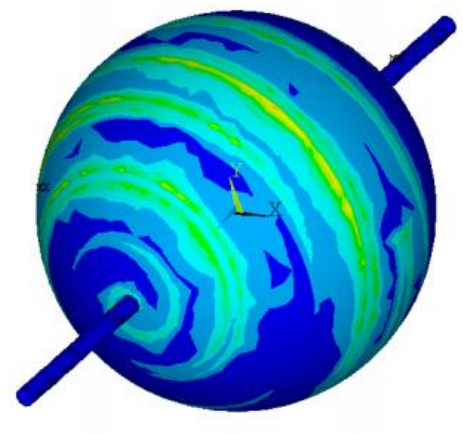

a)

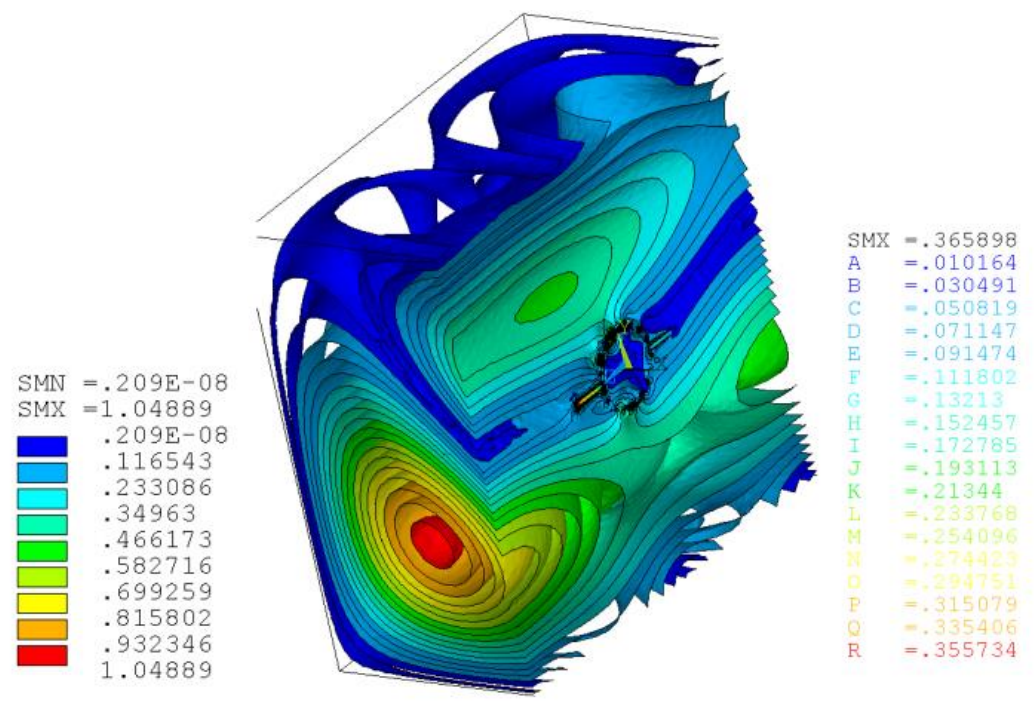

b)

Fig. 8. The evaluation of the electric intensity $E[\mathrm{~V} / \mathrm{m}]$ in the modeled spiral arrangement of the wires, related to the volume for frequency $f=1 \mathrm{GHz}$ : a) at the sphere volume; $b$ ) around the spiral sphere volume

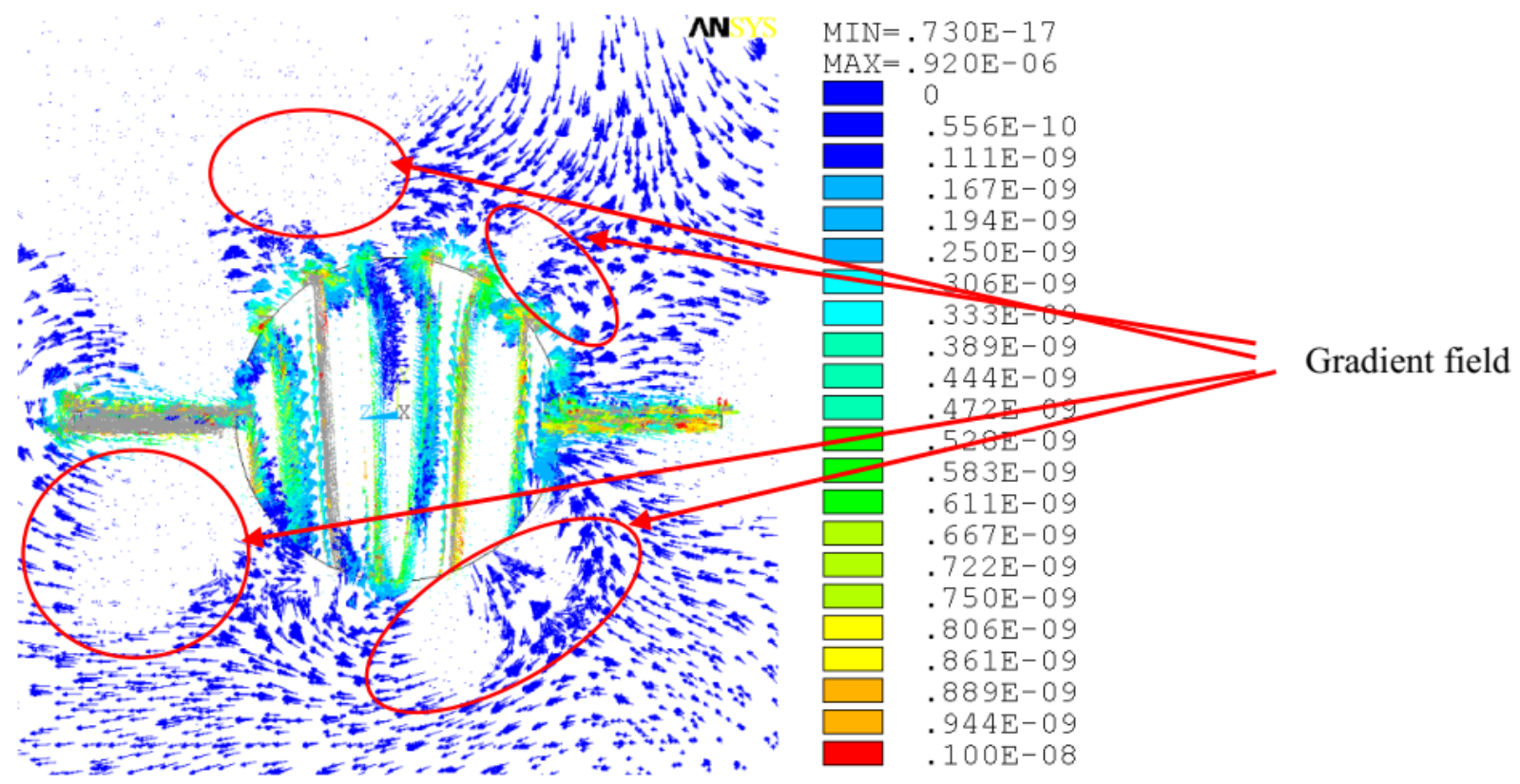

Fig. 9. The evaluation of the Poynting vector $\Pi\left[\mathrm{W} / \mathrm{m}^{2}\right], f=1 \mathrm{GHz}$ in the modeled gradient spiral arrangement of the wires

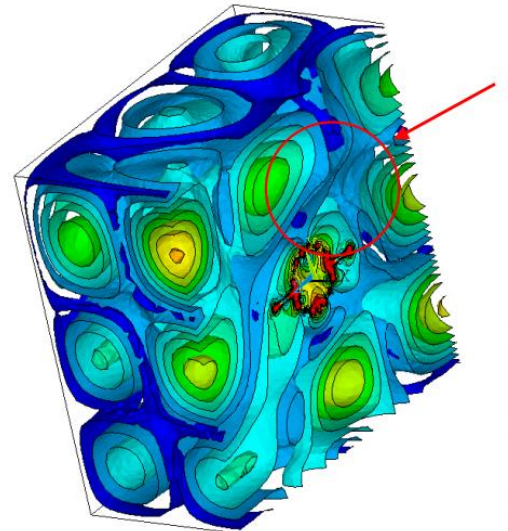

Gradient field

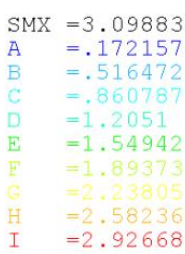

Fig. 10. The evaluation of the electric intensity $E[\mathrm{~V} / \mathrm{m}], f=2 \mathrm{GHz}$ in the modeled spiral arrangement of the wires

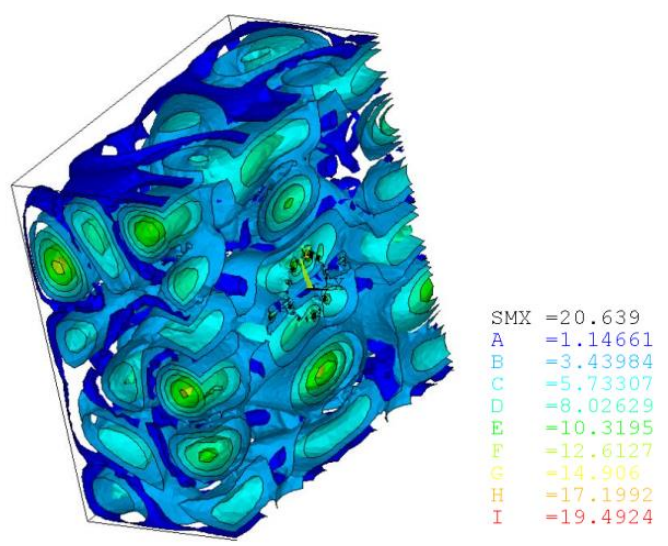

Fig. 11. The evaluation of the electric intensity $E[\mathrm{~V} / \mathrm{m}], f=3 \mathrm{GHz}$ in the modeled spiral arrangement of the wires 


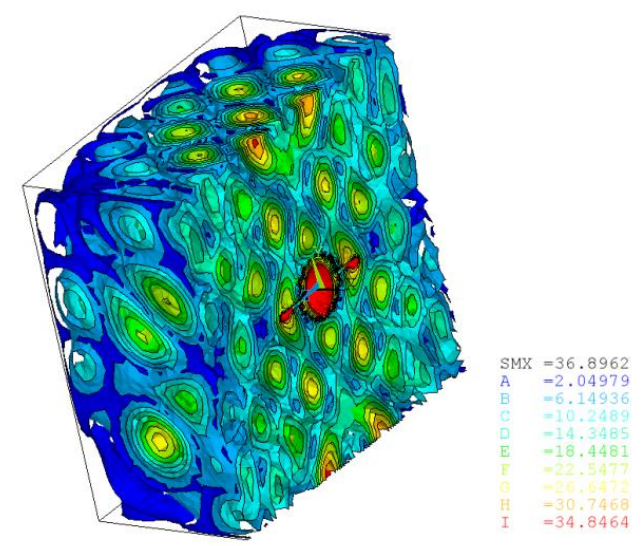

Fig. 12. The evaluation of the electric intensity $E[\mathrm{~V} / \mathrm{m}], f=4 \mathrm{GHz}$ in the modeled spiral arrangement of the wires

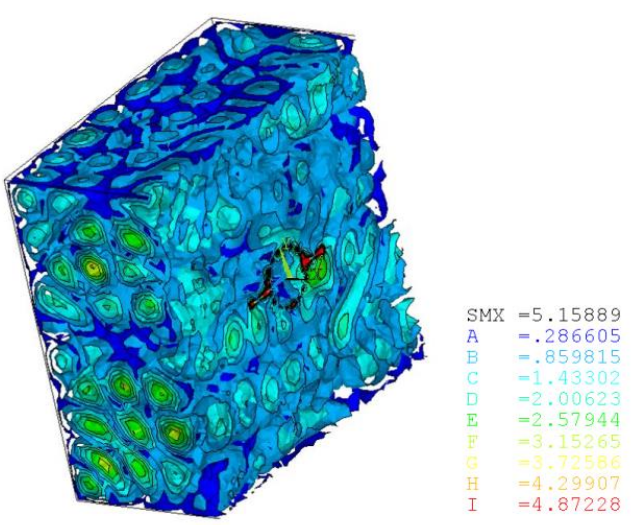

Fig. 13. The evaluation of the electric intensity $E[\mathrm{~V} / \mathrm{m}], f=5 \mathrm{GHz}$ in the modeled spiral arrangement of the wires

\section{Discussion}

Figure 8a details the electromagnetic field and components of electric field intensity $\mathrm{E}$ in the vicinity of the electromagnetic wave excitation element, namely, a spiral antenna, at the excitation frequency of $f=1 \mathrm{GHz}$. Figure $8 \mathrm{~b}$ then shows, for the same frequency, the distribution characterizing the vicinity of the antenna; the environment is clearly unsymmetrical and has the properties of a gradient field. From the perspective of the water system dynamics and the velocity of molecular and atomic motion, the frequency of $\mathrm{f}=1 \mathrm{GHz}$ is very low; thus, the resulting impact on changes in the system of the water sample may be considered equivalent, as in the case of the model with permanent magnets, Fig. 6a. The representation of the Poynting vector $\Pi(\mathrm{t})$ in Fig. 9 indicates that the nanodynamics of the tested water sample are influenced by the preset electromagnetic field of the spiral member. At the given excitation frequency, we can observe the gradient vector distribution outside the antenna. If the frequency increases $(\mathrm{f}=2-10 \mathrm{GHz}$ ), the magnitude and density of the regions with gradient distribution of the electromagnetic field will vary, Figs. 10-14. The magnitude of module E corresponds to the modeled antenna and its impedance matching for the analysis. The density of the regions with the gradient component of the field is a parameter we can adhere to in the experiments, expecting corresponding changes and sizes of the water clusters.

The micro/nanoscopic behavior of a water sample as a low periodicity system is further correlated to numerical modelling [22]. Experiments based on analyses of the electromagnetic field of the given hybrid model were characterized and released within dedicated papers $[5,38]$.
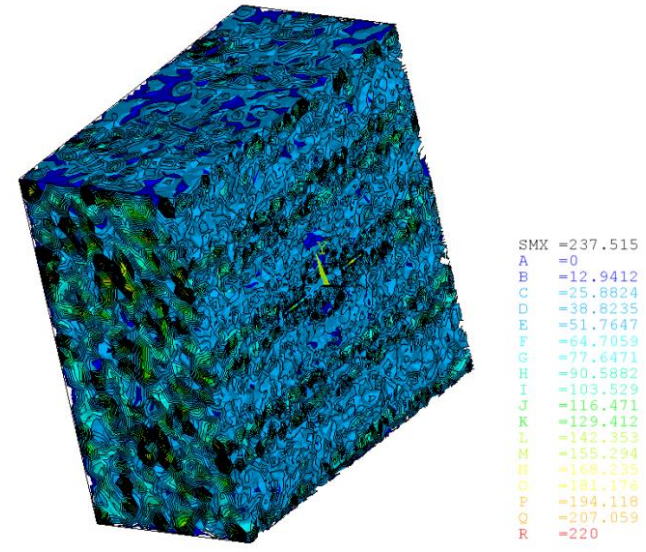

Fig. 14. The evaluation of the electric intensity $E[\mathrm{~V} / \mathrm{m}], f=10 \mathrm{GHz}$ in the modeled spiral arrangement of the wires

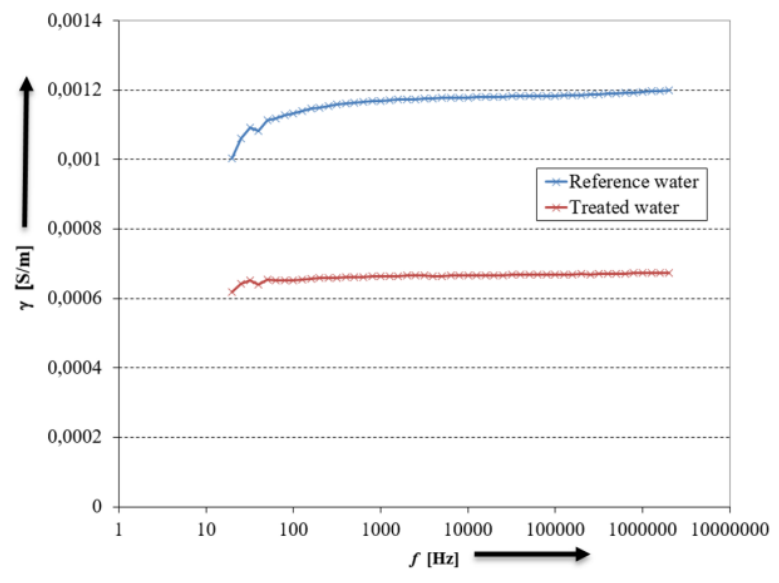

Fig. 15. The conductivities of the reference and the treated water samples related to frequencies: measurement series No. 1

\section{Conclusion}

The results obtained from an analysis centered on the setting of the magnetic bands (permanent magnets, HF spiral antenna) pointed to an interesting distribution of the magnetic field in the monitored space from the qualitative and the quantitative perspectives.

At the initial stage, we designed a numerical model to assess the bond between the macroscopic and micro-nanoscopic models of matter, allowing for an evaluation of the relationships between an external electromagnetic field and the internal dynamic systems of both inorganic and organic or live matter [3, 4, 5, 22, 27, 38].

Exploiting relevant analyses of the numerical model, we then set up different experimental measurements, tested the samples of $\mathrm{H}_{2} \mathrm{O}$, and examined the macroscopic physical properties of the magnetically or electromagnetically treated water $[5,38]$.

\section{Acknowledgements}

The research was financed from National Sustainability Program under grant No. LO1401 and supported within a grant of Czech Science Foundation (GA 17-00607S). For the actual analyses and experiments, the infrastructure of the SIX Center was utilized.

\section{References}

[1] ANSYS, Ansys Multiphysics Manuals, Ansys,(1994-2018), Houston, USA.

[2] Bakker H.J., Kropman M.F., Omta A.W.: Effect of ions on the structure and dynamics of liquid water. J. Phys. Condensed Matter 17/2005, 3215-3224.

[3] Bartušek K., Fiala P., Mikulka J.: Numerical Modeling of Magnetic Field Deformation as Related to Susceptibility Measured with an MR System. Radioengineering 17(4)/2008, 113-118. 
[4] Bartušek K., Gescheidtová E., Mikulka J.: Data Processing in Studying Biological Tissues, Using MR Imaging Techniques, 33 th International Conference on Telecommunications and Signal Processing. Budapešt': Asszisztenda Szervezo, 2010, 171-175.

[5] Bartušek K., Marcoň P., Fiala P., Máca J., Dohnal P.: The Effect of a Spiral Gradient Magnetic Field on the Ionic Conductivity of Water. Water 9(9)/2017, $1-8$.

[6] Chaplin M.: http://www1.lsbu.ac.uk/water/water_structure_science.html

[7] Chaplin M.F.: A proposal for the structuring of water. Biophysical Chemistry 83/1999, 211-221.

[8] Clary D. C.: Quantum dynamics in the smallest water droplet. Science 351/2016, 1267-1268.

[9] Cole W. T. S., Farrell J. D., Wales D. J., Saykally R. J.: Structure and torsional dynamics of the water octamer from THz laser spectroscopy near $215 \mu \mathrm{m}$. Science 352/2016, 1194-1197.

[10] Drexler P., Fiala P.: Power supply sources based on resonant energy harvesting. Microsystem Technologies 18(7,8)/2012, 1181-1192.

[11] Drexler P., Kadlec R., Bartušek K., Fiala P., Kubásek R.: Magnetoinductive Lens for Experimental Mid- field MR Tomograph. In Proceedings of PIERS 2010 in Cambridge. Cambridge 2010, 1047-1050.

[12] Elia V., Marchettini N., Napoli E., Tiezzi E.: Nanostructures of Water Molecules in Iteratively Filtered Water. Water 7/2016, 147-157.

[13] Elia V., Niccoli M.: New physico-chemical properties of water induced by mechanical treatments. J. Therm. Anal. Calor. 61/2000, 527-537.

[14] Fiala P., Friedl M.: Application of an Electromagnetic Numerical Model in Accurate Measurement of High Velocities. IAPGOS 3/2015, 3-10.

[15] Fiala P., Jirků T., Gescheidtová E.: Tuned Structures for Special THz Applications. Proceedings of the Progress In Electromagnetics Research symposium. Cambridge The electromagnetics academy 2009, 151-155.

[16] Fiala P.: Pulse- powered virtual cathode oscillator. Transactions on Dielectrics and Electrical Insulation 18(4)/2011, 1046-1053.

[17] Frank H. S., Wen W.-Y.: Ion-solvent interaction. Structural aspects of ionsolvent interaction in aqueous solutions: a suggested picture of water structure. Faraday Discussions 24/1957, 133-140.

[18] Goncharuk V. V., Kavitskaya A. A., Romanyukina I. Y., Loboda O. A.: Revealing water's secrets: deuterium depleted water. Chemistry Central Journal 7/2013, 103.

[19] Hansen T. C., Falenty A., Kuhs W. F.: Modelling ice Ic of different origin and stacking-faulted hexagonal ice using neutron powder diffraction data, in Physics and Chemistry of Ice, ed. W. Kuhs. Royal Society of Chemistry, Cambridge, 2007, 201-208.

[20] Ignatov I., Mosin O.: Structural Mathematical Models Describing Water Clusters. Mathematical Theory and Modeling 3(11)/2013.

[21] Ikeshoji T., Aihara T., Ohno K., Kawazoe Y.: Ab-initio Molecular Dynamics Simulation of Water Clusters. Sci. Rep. RITU A41/1996, 175-182.

\section{Prof. Pavel Fiala \\ e-mail: fialap@feec.vutbr.cz}

Received Ph.D. in electrical engineering from the Brno University of Technology, Faculty of Electrical Engineering and Communication in 1998. He joined the Department of Theoretical and Experimental Electrical Engineering in 1990 as a research assistant. Since 2003 he has been an associate professor and head of the Department of Theoretical and Experimental Electrical Engineering. Dr. Fiala is interested in the modelling and analysis of coupled field problems by numerical methods formulated with partial differential equations using the finite element method (FEM), the boundary element method (BEM), and the finite difference method (FDM). He is since 09.2014 full proffesor of The Theoretical and Electrical Engineering. Pavel Fiala is a member of the SPIE, APS, OSA, The Electromagnetic Academy, Cambridge, USA (since 2007) and a reviewer of the Elsevier, IEEE, Springer. Journals etc.

ORCID ID: 0000-0002-7203-9903

\section{Prof. Karel Bartušek}

e-mail: bar@isibrno.cz

Was born in Brno, Czech Republic, in 1948. $\mathrm{He}$ received the Ing. (M.Sc.) degree in Electrical Engineering in 1973, the CSc. (Ph.D.) degree in 1983, Dr.Sc. degree in 1998 and Prof. degree in 2008. $\mathrm{He}$ works as an independent scientific worker on Institute of Scientific Instruments in Brno, Academy of Sciences of the Czech Republic and as a scientific worker on Brno University of Technology, Faculty of Electrical Engineering and Communication. He is author/co-author over 200 scientific publications. His research interests are in general area of new

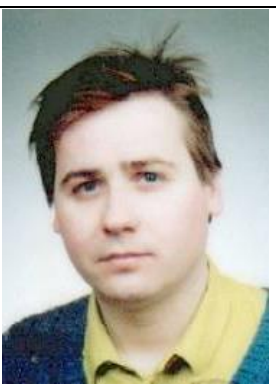
multiparametric MR techniques. Main problem is DW MR imaging measurements, relaxation times, study of dynamic MRI examinations for medical use.
[22] Kadlec R., Fiala P.: The Response of Layered Materials to EMG Waves from a Pulse Source. Progress In Electromagnetics Research M. 42/2015, 179-187.

[23] Krishnan M., Verma A., Balasubramanian S.: Proc. Indian Acad. Sci. (Chem. Sci.) $113(5,6) / 2001,579-590$.

[24] Kuhs W. F., Sippel C., Falenty A., Hansen T. C.: Extent and relevance of stacking disorder in "ice Ic". Proceedings of the National Academy of Sciences 109/2012, 21259-21264.

[25] Malkin T. L., Murray B. J., Brukhno A. V., Anwar J., Salzmann C. G.: Structure of ice crystallized from supercooled water. Proceedings of the National Academy of Sciences 109/2012, 1041-1045.

[26] Malkin T. L., Murray B. J., Salzmann C. G., Molinero V., Pickering S. J., Whale T. F.: Stacking disorder in ice I. Physical Chemistry Chemical Physics 17/2015, 60-76.

[27] Marcoň P., Bartušek K., Mikulka J., Čáp M.: Magnetic susceptibility modelling using ANSYS. Progress In Electromagnetics 2011, 190-193.

[28] Moore E. B., Molinero V.: Is it cubic? Ice crystallization from deeply supercooled water. Physical Chemistry Chemical Physics 13/2011, 20008-20016.

[29] Mootz D., Seidel R.: Polyhedral clathrate hydrates of a strong base: phase relations of crystal structures in the system tetramethylammonium hydroxidewater. J. Inclusion Phenomena 8/1990, 139-157.

[30] Muscia R.: Equivalent magnetic charge in helicoidal magnets. J. Appl. Phys. 104/2008, 103916.

[31] Ohmine I., Tanaka H.: Chem. Rev. 93/1993, 2545.

[32] Perera A., Mazighi R., Kežíc B.: Fluctuations and micro-heterogeneity in aqueous mixtures. Journal of Chemical Physics 136/2012, 174516

[33] Perera A.: On the microscopic structure of liquid water. Molecular Physics 109/2011, 2433-2441.

[34] Rahman A., Stillinger F. H.: J. Chem. Phys. 55/1971, 3336.

[35] Richardson J. O., Pérez C., Lobsiger S., Reid A. A., Temelso B., Shields G. C. Kisiel Z., Wales D. J., Pate B. H., Althorpe S. C.: Concerted hydrogen-bond breaking by quantum tunneling in the water hexamer prism. Science 351/2016, 1310-1313.

[36] Shelton D. P.: Long-range orientation correlation in water. Journal of Chemical Physics 141/2014, 224506.

[37] Stratton J. A.: Electromagnetic field theory. SNTL, Praha 1961.

[38] Vlachová Hutová E., Bartušek K., Dohnal P., Fiala P.: The Influence of a Static Magnetic Field on the Behavior of a Quantum Mechanical Model of Matter. Measurement, Journal of the International Measurement Confederation (IMEKO) 96/2017, 18-23.

[39] Vostrikov A.A., Drozdov S.V., Rudnev V.S., Kurkina L.I.: Molecular dynamics study of neutral and charged water clusters. Computational Materials Science 35/2006, 254-260

[40] Weisstein E.W.: Galerkin Method, MathWorld, 28 March 2015 http://mathworld.wolfram.com/GalerkinMethod.html. 1 April 2015

\section{Prof. Jarmila Dědková}

e-mail: dedkova@feec.vutbr.cz

Jarmila Dědková is professor of Theoretical electrical engineering at the Department of Theoretical and Experimental Electrical Engineering, Faculty of Electrical Engineering and Communication Brno University of Technology. From 2003 to 2010 she was vice-dean for study at FEEC BUT, from 2010 to 2018 she was dean of FEEC BUT and since 2018 she is vice-dean for study at FEEC BUT.

She is interested in numerical modeling (BEM, FEM) of electromagnetic fields, first of all in research and development of new algorithms for effective solutions of inverse problems, numerical methods for image reconstructions based on electrical impedance tomography. She lectures subjects Modeling of electromagnetic fields and Electrical engineering of undergraduate as well as postgraduate courses.

ORCID ID: 0000-0002-7919-0489

\section{M.Sc. Premysl Dohnal}

e-mail: dohnalp@feec.vutbr.cz

Přemysl Dohnal graduated from Masaryk University, Brno, in 2007. He is currently a lecturer at the Department of Theoretical and Experimental Electrical Engineering, Brno University of Technology. His professional interests are the language of technology, teaching, and laboratory research of electric circuits.

ORCID ID: 0000-0003-1163-4458

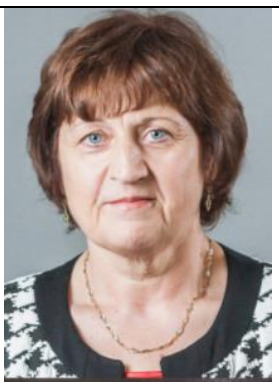

